\title{
Land use temporarily affects active pond-community structure but not gene expression patterns
}

\author{
Mina Bizic ${ }^{1}$, Danny Ionescu ${ }^{1}$, Rajat Karnatak ${ }^{2}$, Camille Musseau ${ }^{2}$, Gabriela Onandia ${ }^{3}$, \\ Stell Berger ${ }^{2}$, Jens Nejstgaard ${ }^{4}$, Gunnar Lischeid ${ }^{3}$, Mark Gessner ${ }^{2}$, Sabine Wollrab ${ }^{2}$, and \\ Hans- Grossart ${ }^{5}$ \\ ${ }^{1}$ Leibniz-Institute of Freshwater Ecology and Inland Fisheries in the Forschungsverbund \\ Berlin eV Department 3 Experimental Limnology \\ ${ }^{2}$ IGB Berlin (Germany) \\ ${ }^{3}$ Leibniz Centre for Agricultural Landscape Research \\ ${ }^{4}$ Leibniz Institute of Freshwater Ecology and Inland Fisheries \\ ${ }^{5}$ IGB-Berlin
}

July 21,2021

\begin{abstract}
Changes in land use and agricultural intensification threaten biodiversity and ecosystem functioning of small water bodies. We studied 67 kettle holes $(\mathrm{KH})$ in an agricultural landscape in northeastern Germany using landscape-scale metatranscriptomics, to understand the responses of active communities across the three domains of life, Bacteria, Archaea, and eukaryotes, to land use. These KH are proxies of the millions of small standing water bodies of glacial origin spread across the northern hemisphere. Like other landscapes in Europe, the study area has been used for intensive agriculture since the 1950s. In contrast to a parallel eDNA study which revealed the homogenization of biodiversity across KH conceivably resulting from long-lasting intensive agriculture, land-use type affected the structure of the active $\mathrm{KH}$ communities during spring crop fertilization, but not a month later. This effect was more pronounced in eukaryotes than in bacteria. In contrast, gene expression patterns did not differ between months or across land-use type, suggesting a high degree of functional redundancy across the KH communities. Variability in gene expression was best explained by active community structure, suggesting that these changes in functioning are primarily driven by interactions between organisms. Our results show that influences of the surrounding landscape result in temporary changes in the activity of different community members. Thus, even in KH where biodiversity has been homogenized, communities continue to respond to land management. This needs to be considered when developing sustainable management options for restoration purposes and for successful mitigation of further biodiversity loss in agricultural landscapes.
\end{abstract}

\section{Hosted file}

Bizic_et_al_MetaTrans_MainText_08072021.pdf available at https://authorea.com/users/426839/ articles/531213-land-use-temporarily-affects-active-pond-community-structure-but-notgene-expression-patterns 